\title{
Pathological Classification of Focal Cortical Dysplasia (FCD) : Personal Comments for Well Understanding FCD Classification
}

\author{
Se Hoon Kim, M.D., Ph.D., EFN., Junjeong Choi, M.D., Ph.D. ${ }^{2}$ \\ Department of Pathology, Severance Hospital, Yonsei University College of Medicine, Seoul, Korea \\ Yonsei Institute of Pharmaceutical Sciences, ${ }^{2}$ College of Pharmacy, Yonsei University, Incheon, Korea
}

In 2011, the International League against Epilepsy (ILAE) proposed a first international consensus of the classification of focal cortical dysplasia (FCD). This FCD classification had been widely used in worldwide. In this review paper, the authors would like to give helpful comments for better understanding of the current FCD classification. Especially, the basic concepts of FCD type I, such as "radial", "tangential" and "microcolumn" will be discussed with figures. In addition, the limitations, genetic progress and prospect of FCD will be suggested.

Key Words : Focal cortical dysplasia · Histology · Classification · Embryology · Pathology.

\section{INTRODUCTION}

Focal cortical dysplasia (FCD) is a heterogeneous group of disorders, which can be the cause of drug-resistant epilepsy or intractable epilepsy ${ }^{12}$. In medical practice, "dysplasia" is used as variable meanings, as pre-neoplastic (e.g., epithelial dysplasia of stomach), developmental anomaly (e.g., renal dysplasia) or etc. Originally "dysplasia" was a term used to refer an abnormality of development, alternation in size, shape and organization of adult cells ${ }^{14,16)}$. Blümcke et al. ${ }^{5)}$ defined this terminology as "any tissue that is imperfectly developed in embryonic or fetal life. However, dysplasia is a diagnostic term used here to identify specific malformations of the cortex, the so-called FCDs, irrespective of their diverse histologic appearances that are addressed by this classification" in their paper ${ }^{5}$. Therefore, it is obvious that FCDs have a meaning of developmental abnormalities including cortical dyslamination, cytoarchitectural lesions, and underlying abnormalities of white matter 5,11 .

\section{THE SHORT HISTORY OF FCD}

In 1971, Taylor et al. ${ }^{13)}$ reported the 10 patients with drugresistant epilepsy and described several histological findings, cortical disorganization, large bizarre neurons and balloon

- Received : January 21, 2019 •Revised : February 9, 2019 •Accepted : February 9, 2019

- Address for reprints : Se Hoon Kim, M.D., Ph.D., EFN.

Department of Pathology, Severance Hospital, Yonsei University College of Medicine, 50-1 Yonsei-ro, Seodaemun-gu, Seoul 03722, Korea Tel : +82-2-2228-1769, Fax : +82-2-362-0860, E-mail : paxco@yuhs.ac

This is an Open Access article distributed under the terms of the Creative Commons Attribution Non-Commercial License (http://creativecommons.org/licenses/by-nc/4.0) which permits unrestricted non-commercial use, distribution, and reproduction in any medium, provided the original work is properly cited. 
cells which are characteristic findings of the current classification of FCDs. In this paper, they described these features as "Focal dysplasias of cerebral cortex". Previously, Crome had described three cases of intractable epilepsy. He described "dysmorphic neurons" as "giant nerve cells" in his cases".

After that, many researchers used different various terminologies in discussing FCDs. Although the etiology is exactly unknown, it is accepted that many lesions are related to the alteration of cortical development caused by a variety of mechanisms ${ }^{12}$. In 1992, Meencke and Veith") introduced "microdysgenesis" as a minor parenchymal malformation in patients with generalized epilepsy. They described many characteristic histological findings from their cases. These findings were largely overlapped with the features in current classification system of FCD. In 1996, the terminology of "malformation of cortical development (MCD)" was introduced to designate collectively a common group of disorders in children with developmental delay and young people with epilepsy²). They categorized these disorders as group I, II, and III. FCD was categorized as group III.B. In the past, MCDs have been defined as "neuronal migration disorder"; however, as not all the cortical abnormalities have been proven to be due to migrational derangements, the general term of MCDs was prefered $^{11}$.

In 2004, Palmini et al. ${ }^{11)}$ suggested FCD classification. After panel discussion, they proposed as follows : 1) a specific terminology for the different types of abnormal cells encountered in the cerebral cortex of patients with FCD; 2) a reappraisal of the different histopathologic abnormalities usually subsumed under the term "microdysgenesis," and suggested that this terminology be abandoned; and 3) a more detailed yet straightforward classification of the various histopathologic features that usually are included under the heterogeneous term of "focal cortical dysplasia."

Therefore, they classified the lesions as mild MCD (mild MCD) and FCD. In addition, they classified each entity into type I and II respectively (Table 1).

With advances in clinical, histological, radiological and genetic understanding of FCDs, International League Against Epilepsy (ILAE) Task Force proposed a three tiered classification system in 2011.

\section{THE CURRENT ILAE CLASSIFICATION SYSTEM OF FCD}

It is better to read the original paper ") "point for point" for understanding of the detailed FCD classification system. In addition, the authors strongly recommend to read Najm et al.'s paper $^{10}$. This paper dealt not only the original classification system, but also updated issue along the new data and prospective suggestions.

In this review paper, the authors would like to give helpful comments for better understanding of the current FCD classification.

\section{Overview}

The ILAE classification system of FCD is based on some several neurodevelopmental studies, especially on Cepeda et al.'s study ${ }^{6}$ in a large portion. They suggested "dysmature cerebral developmental hypothesis" which is a partial failure in

Table 1. Classification of cortical dysplasias in epilepsy ${ }^{11)}$

\begin{tabular}{|c|c|c|}
\hline $\begin{array}{l}\text { Focal dysplasia } \\
\text { type }\end{array}$ & Subtype & Main neuropathological features \\
\hline \multirow[t]{2}{*}{ Mild MCD } & Type I & Heterotopic/excess neurons in layer I \\
\hline & Type II & $\begin{array}{l}\text { Heterotopic/excess neurons outside in } \\
\text { layer I }\end{array}$ \\
\hline \multirow[t]{2}{*}{ FCD type I } & Type la & $\begin{array}{l}\text { Cortical dyslamination only ( } \pm \text { MCD } \\
\text { features) }\end{array}$ \\
\hline & Type lb & $\begin{array}{l}\text { Cortical dyslamination+giant* or } \\
\text { immature neurons }{ }^{\dagger}\end{array}$ \\
\hline \multirow[t]{2}{*}{$\begin{array}{l}\text { FCD type } \| \\
\text { (Taylor-type) }\end{array}$} & Type lla & $\begin{array}{l}\text { Cortical dyslamination+dysmorphic } \\
\text { neurons }^{\ddagger}\end{array}$ \\
\hline & Type Ilb & $\begin{array}{l}\text { Cortical dyslamination+dysmorphic } \\
\text { neurons and balloon cells }\end{array}$ \\
\hline
\end{tabular}

In Palmini's classification, 'giant neurons' were described focusing on cell size. In the other hand, 'dysmorphic neurons' were described focusing abnormal morphology and aggregated coarse Nissl substance. The abnormal neurons in Fig. 5B are similar to the 'giant neurons' and cells in Fig. 6B are more similar to the 'dysmorphic neurons' in Palmini et al.'s classification. In the current classification, the definition of dysmorphic neuron has two morphological features, both large size and the characteristic Nissl substance. According to Palmini et al.'s classification ${ }^{11)}$, * giant neurons are neurons of increased size (compared with layer $V$ pyramidal neurons) with central nuclei. ${ }^{\dagger}$ The immature neurons are round cells with immature nucleus, not dysmorphic or giant. They could be seen in heterotopic nodules. "Dysmorphic neurons are cells with abnormal orientation, size, cytoskeletal structures and atypical dendritic processes. Nissl substance can be seen in clumps. MCD : malformation of cortical development, FCD : focal cortical dysplasia 
later phases of cortical development might show the distinctive histopathology, such as cortical dysplasia And local interactions of dysmature cells with normal postnatal neurons might promote seizures. Especially the basic concept of FCD type I was established from the Hildebrandt et al.'s morphometric study ${ }^{8}$.

On contrary to Palmini et al.'s system ${ }^{11)}$, The ILAE classification system of FCD has a three-tier system. This system composed of isolated FCDs (FCD type I and II) and variants associated with other (potentially) epileptogenic lesions (FCD type III). The definition of FCD type III was cortical dyslamination abnormalities associated with a principal lesion, usually adjacent to or affecting the same cortical area/lobe ${ }^{3)}$. The basic concept of type III seems to base on that there were some disturbances of normal cortical six layers adjacent the main lesion. In addition, it might be very difficult to identify these "subtle" cortical abnormalities from the histologic changes of "secondary reactive process, resulting from the main lesions.

Meanwhile, the mild MCD (mMCD) was not included the current system ${ }^{3)}$. Therefore, the mMCDs in Blümcke et al.'s paper ${ }^{4)}$ were classified according to the Palmini et al.'s classification $^{11)}$.

To get the best possible histologic assessment and reduce sampling errors, the standardized procedures for inspection, distribution and processing of epileptogenic brain tissue are

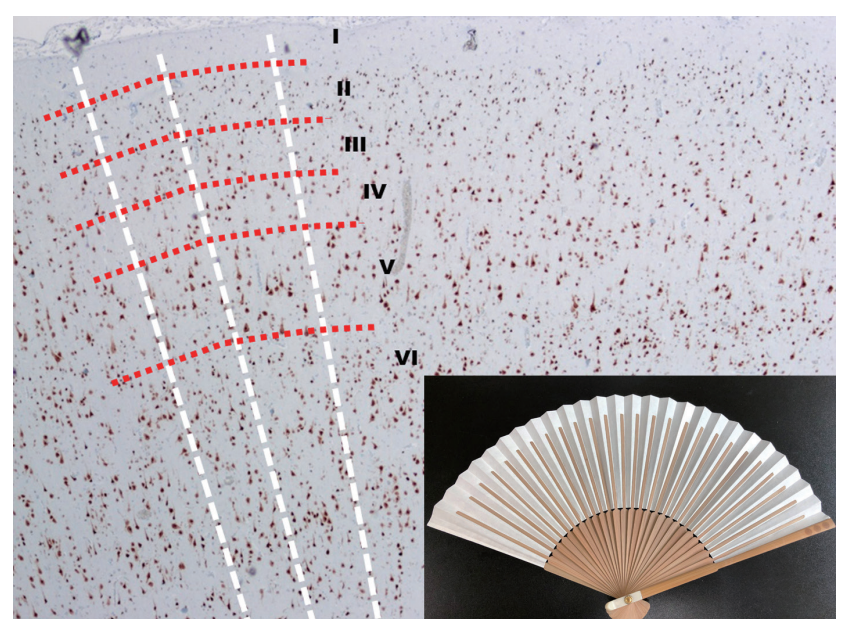

Fig. 1. The low power view of normal neocortex $(\mathrm{NeuN}, \times 40)$ and $a$ Korean folding pan (inlet). The imaginary white lines show the direction of radial migrations of neural cells. The lines look like the bones of a folding pan (inlet). The cortical six-layers were seen with red imaginary lines. The red imaginary lines show the tangential composition of neocortex. In the normal neocortex, it is unusual that the neuronal cells exactly align along the white imaginary lines. very important ${ }^{3)}$. Especially, the surgical procedures, resulting on piecemeal fragmentations of tissue should be avoided for pathologic diagnosis. The Task Force of ILAE commission on Diagnostic Methods suggested the International recommendation for a comprehensive neuropathologic workup of epilepsy surgery brain tissue ${ }^{3)}$. They emphasized an en-bloc resection, anatomical oriented landmarks and $5 \mathrm{~mm}$ serial cutting, perpendicular to the pia. The immunohistochemical staining had become a routine procedure for the diagnosis. For example, the neuronal markers (e.g., NeuN) are essential to diagnosis certain type of FCD, especially in type I.

They defined the words, "dual pathology" and "double pathology". They proposed the "dual pathology" as only in hippocampal sclerosis (HS), a second principal lesion affecting the brain, that is, tumor, vascular malformation, glial scar, limbic/Rasmussen encephalitis, or MCD (including FCD type $\mathrm{IIa} / \mathrm{IIb})^{5}$. If there is an architectural abnormality in the temporal lobe in HS patients, we should diagnosis as FCD type IIIa, instead of FCD type I or dual pathology. The double pathology meant that two independent lesions affecting one or multiple lobe, without HS. It meant that both lesions might originate from independent pathogenesis. For example; cavernous angioma in right temporal lobe and ganglioglioma in left temporal lobe.

In summary, 1) If HS plus FCD type I features in the temporal lobe is FCD type IIIa. 2) If HS plus other lesion (FCD type II, tumor, scar, or encephalitis) is a dual pathology. And 3) lesion A

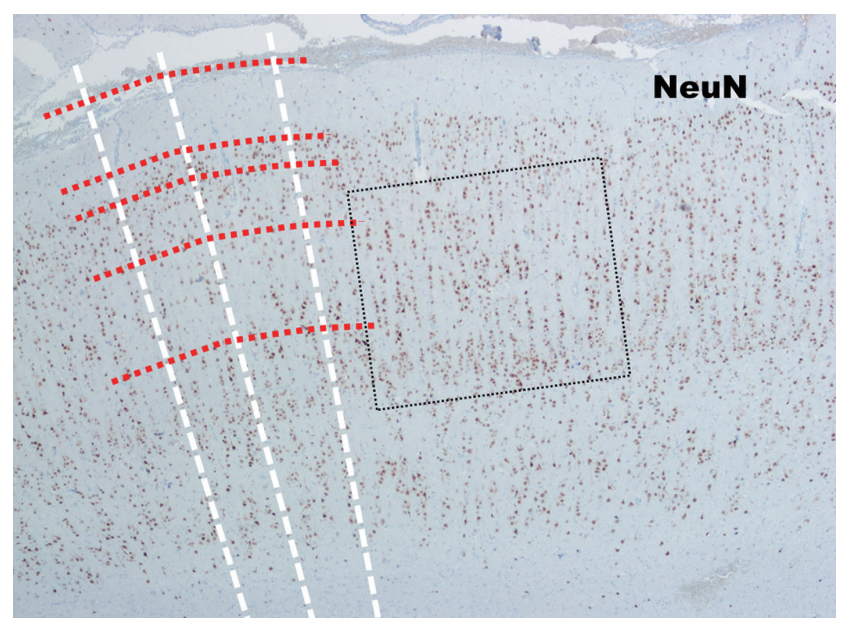

Fig. 2. The low power view of the neocortex in FCD type la (NeuN, $\times 40$ ). In contrast to the normal neocortex, many neuronal cells in FCD type la show linear alignment as shown in the dot-line box. FCD : focal cortical dysplasia. 
(except HS) plus lesion B (except HS) is a double pathology.

The clinico-radiologic-pathological correlation is very essential in diagnosis. For example, the histological features of hemimegalencephaly, tuberous sclerosis or schizencephaly could be overlapped with FCD type $\mathrm{II}^{5}$. Comprehensive review of patient clinical information would provide a diagnos-

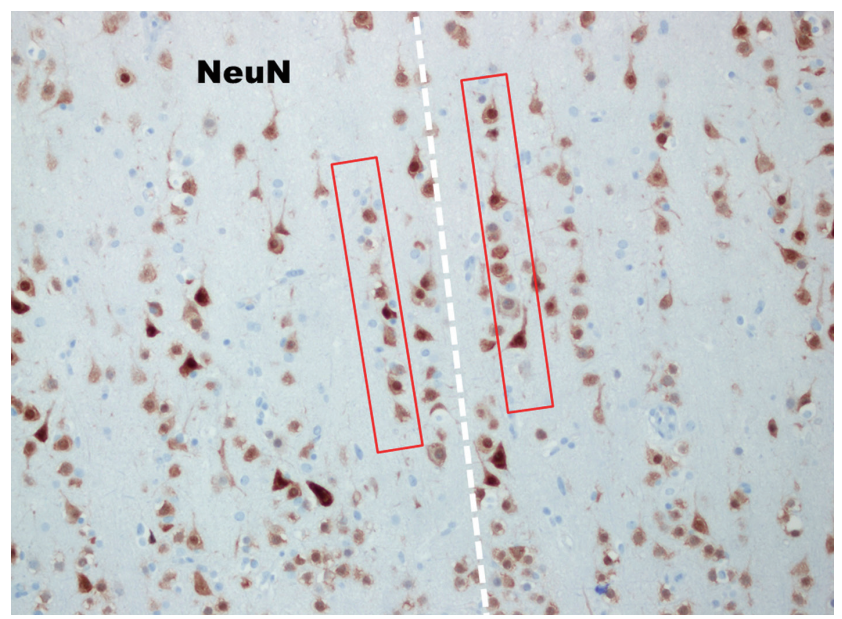

Fig. 3. In high power view of the box (NeuN, $\times 200)$, the so-called many microcolumns, which were defined more than eight neurons aligned in a vertical direction, are noted (red boxes).

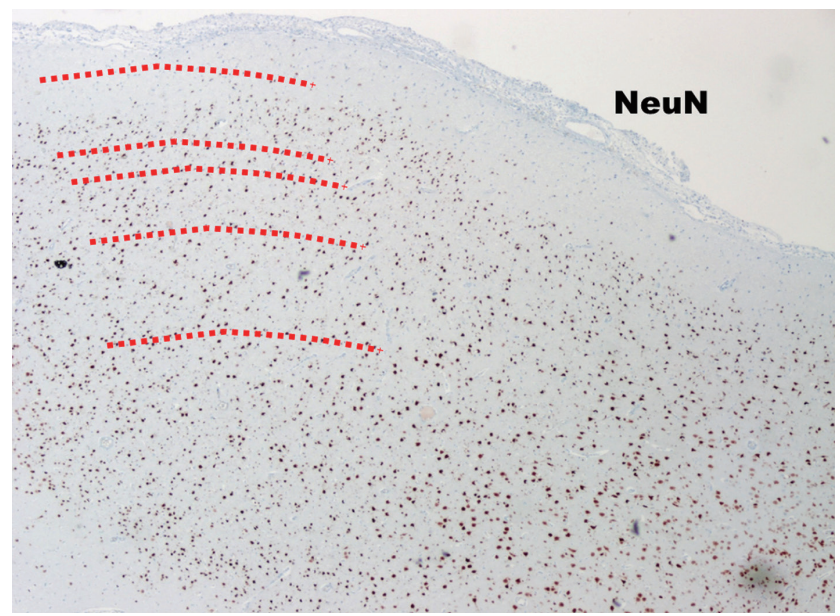

Fig. 4. The low power view of FCD type lb $(\mathrm{NeuN}, \times 40)$. The cortical sixlayers are deranged (too chaotic) compared to those in normal neocortex (Fig. 1). FCD : focal cortical dysplasia.
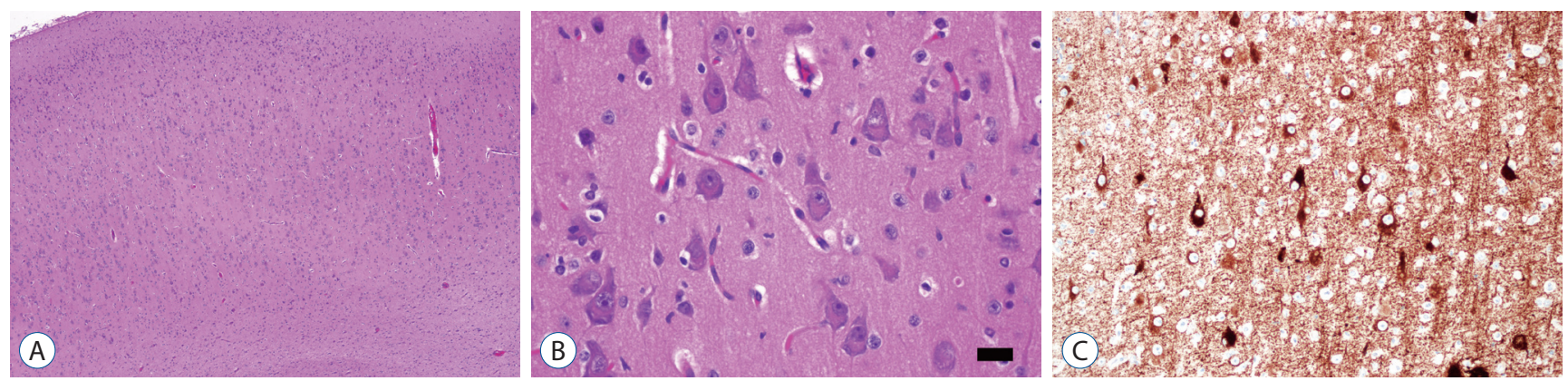

Fig. 5. The histopathological findings of $F C D$ type lla. The low power view $(A ; H-E, \times 40)$ shows cortical dyslamination which means derangement of normal neocortical six-layers. High power view shows many large dysmorphic neurons with coarse Nissl substances. The size of dysmorphic neuron cytoplasm is more than $20 \mu \mathrm{m}(\mathrm{B} ; \mathrm{H}-\mathrm{E}, \times 400$; black bar, $20 \mu \mathrm{m})$. Dysmorphic neurons are highlighted by immunostaining with nonphosphorylated neurofilament (C; SMI132, ×200). FCD: focal cortical dysplasia.
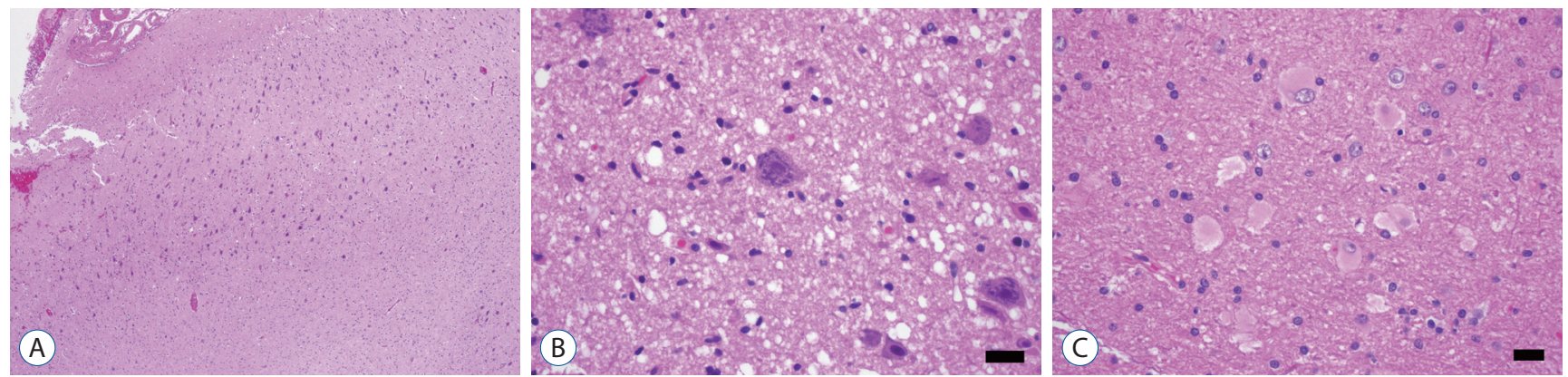

Fig. 6. The histopathological findings of FCD type llb. The low power view $(A ; H-E, \times 40)$ shows cortical dyslamination as FCD type lla. High power view shows many large dysmorphic neurons with coarse Nissl substances $(\mathrm{B} ; \mathrm{H}-\mathrm{E}, \times 400$; black bar, $20 \mu \mathrm{m})$ and balloon cells showing eosinophilic homogenous cytoplasm ( $\mathrm{C}$; $\mathrm{H}-\mathrm{E}, \times 400$; black bar, $20 \mu \mathrm{m})$. FCD : focal cortical dysplasia. 
tic clue.

\section{FCD type I}

FCD Type I is a malformation characterized by abnormal cortical layering, which is caused by abnormal process in either radial migration of neurons (FCD type Ia) or the six-layered tangential composition of the neocortex (FCD type Ib). The combination of both conditions will be classified as FCD type $\mathrm{Ic}^{5}$. Before the understanding of the pathology of FCD type Ia, we have to remind what are "radial" and "tangential" (Fig. 1). Because the neuronal progenitor cells migrate along the radial glial cells, the radial migration looks like the bones of "a folding pan (Fig. 1, inlet)" in the microscopic examina- tion (Fig. 1, white lines). And it is important to understand the definition of "microcolumn"5). The definition of "microcolumn" is more than eight neurons aligned in a vertical direction (Figs. 2 and 3). The concept of microcolumn was firstly introduced in Hildebrandt et al's paper ${ }^{8)}$. On their observation, the cells of microcolumn had smaller perikarya. During the developmental period, primitive neuronal cells start to differentiate to several types and sizes after 22-weeks of gestation and the microcolumns begin to disappear ${ }^{10}$. The pattern of microcolumn is unusual histological findings in postnatal controls ${ }^{8)}$ (Fig. 1), except for occipital area. These findings suggested that the cortical maturation arrest may cause FCD type Ia.

The tangential compositions of the neocortex are completed

Table 2. The current three-tired ILAE classification system of FCD

\begin{tabular}{|c|c|c|c|c|}
\hline FCD type I (isolated) & $\begin{array}{l}\text { Focal cortical dysplasia with } \\
\text { abnormal radial cortical } \\
\text { lamination (FCD type la) }\end{array}$ & $\begin{array}{l}\text { Focal cortical dysplasia } \\
\text { with abnormal tangential } \\
\text { cortical lamination (FCD } \\
\text { type Ib) }\end{array}$ & \multicolumn{2}{|c|}{$\begin{array}{l}\text { Focal cortical dysplasia with abnormal radial and } \\
\text { tangential cortical lamination (FCD type Ic) }\end{array}$} \\
\hline FCD type II (isolated) & \multicolumn{2}{|c|}{$\begin{array}{l}\text { Focal cortical dysplasia with dysmorphic neurons (FCD } \\
\text { type lla) }\end{array}$} & \multicolumn{2}{|c|}{$\begin{array}{l}\text { Focal cortical dysplasia with dysmorphic neurons and } \\
\text { balloon cells (FCD type Illb) }\end{array}$} \\
\hline $\begin{array}{l}\text { FCD type III (associated with } \\
\text { principal lesion) }\end{array}$ & $\begin{array}{l}\text { Cortical lamination } \\
\text { abnormalities in the } \\
\text { temporal lobe associated } \\
\text { with hippocampal sclerosis } \\
\text { (FCD type IIla) }\end{array}$ & $\begin{array}{l}\text { Cortical lamination } \\
\text { abnormalities adjacent to a } \\
\text { glial or glioneuronal tumor } \\
\text { (FCD type Illb) }\end{array}$ & $\begin{array}{l}\text { Cortical lamination } \\
\text { abnormalities adjacent to } \\
\text { vascular malformation (FCD } \\
\text { type IIIc) }\end{array}$ & $\begin{array}{l}\text { Cortical lamination } \\
\text { abnormalities adjacent to } \\
\text { any other lesion acquired } \\
\text { during early life, e.g., } \\
\text { trauma, ischemic injury, } \\
\text { encephalitis (FCD type IIId) }\end{array}$ \\
\hline
\end{tabular}

FCD type III (NOS) : if clinically/radiologically suspected principal lesion is not available for microscopic inspection. Please note that the rare association between FCD type Ila and IIb with hippocampal sclerosis, tumors, or vascular malformations should not be classified as FCD type III variant. ILAE : international league against epilepsy, FCD : focal cortical dysplasia, NOS : not otherwise specified
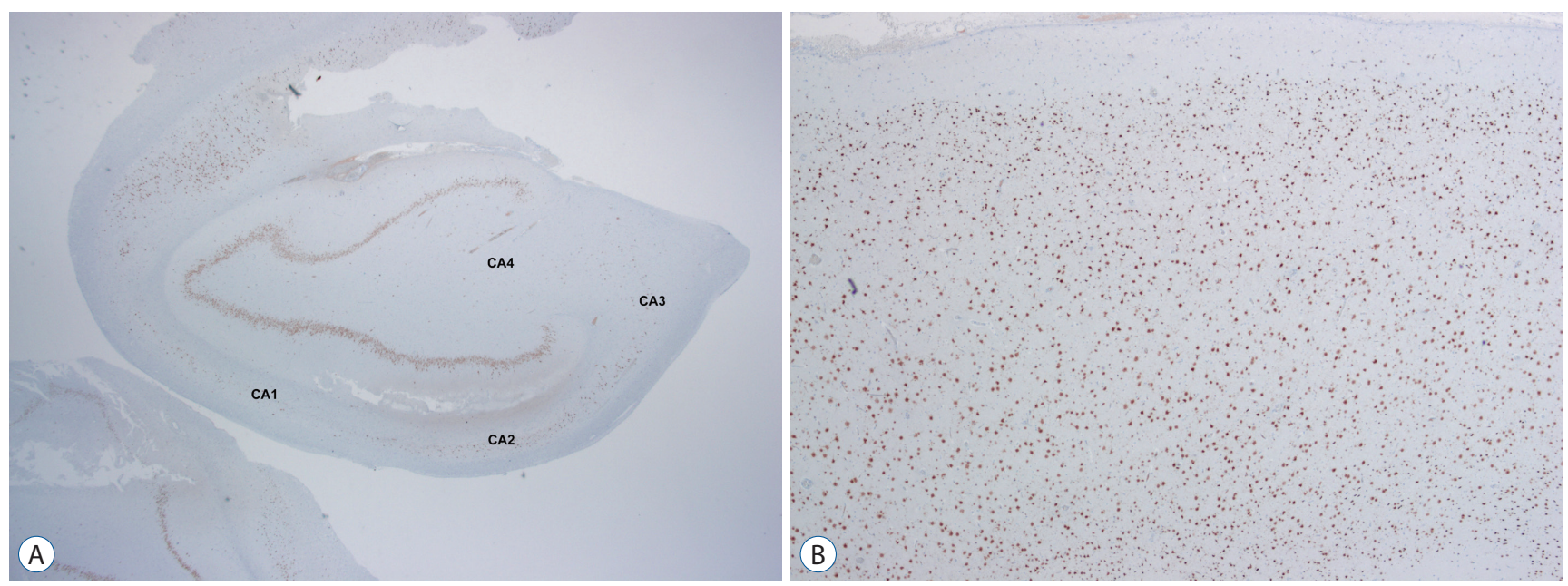

Fig. 7. FCD type Illa is a hippocampal sclerosis (ILAE type la) showing neuronal loss in CA4, 3, 2 and 1 ( $A$; NeuN, $\times 12$ ) with associating FCD type Ib which shows a breakdown of cortical tangential composition in overlying cortex ( $\mathrm{B} ; \mathrm{NeuN}, \times 40)$. FCD : focal cortical dysplasia. 
after the radial migration. The tangential composition looks like "concentric lamella" (Fig. 1, red lines). Usually The FCD type Ib shows the derangements of cortical six-layers (Fig. 4).

The FCD type Ic is the combination of both variants. Even the neuropathologic experts doubts whether it is real entity or not.
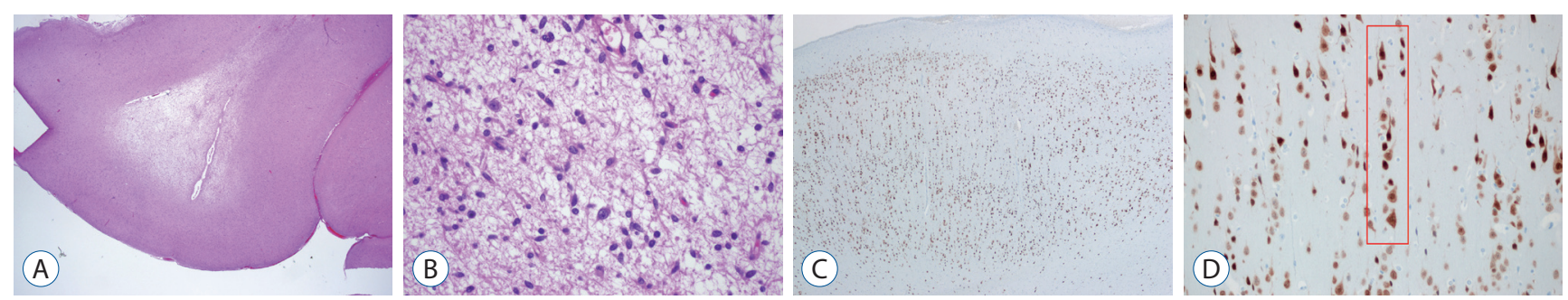

Fig. 8. FCD type Illb is combined with a low grade-epilepsy associated tumor (LEAT). Diagnosis of "the associated tumor" in this case is dysembryoplastic neuroepithelial tumor (DNT) $(A ; H-E, \times 12$ and $B ; H-E, \times 200)$. Overlying cortex shows FCD type la $(C ; N e u N, \times 40)$ characterized by microcolumns ( $D ;$ red box; NeuN, $\times 200)$. $\mathrm{FCD}$ : focal cortical dysplasia.

Table 3. Suggestions for an update to the ILAE classification of FCD ${ }^{10)}$

\begin{tabular}{|c|c|c|c|}
\hline & Histology & Update needed & Comments \\
\hline \multicolumn{4}{|c|}{ FCD type I (isolated) } \\
\hline FCD type la & Abnormal radial cortical lamination & Yes & $\begin{array}{l}\text { Molecular biomarkers needed to confirm specific } \\
\text { pathomechanism }\end{array}$ \\
\hline FCD type lb & Abnormal tangential cortical lamination & Yes & $\begin{array}{l}\text { Molecular biomarkers needed to confirm specific } \\
\text { pathomechanism }\end{array}$ \\
\hline FCD type IC & $\begin{array}{l}\text { Abnormal radial and tangential cortical } \\
\text { lamination }\end{array}$ & No & $\begin{array}{l}\text { Molecular biomarkers needed to confirm specific } \\
\text { pathomechanism }\end{array}$ \\
\hline \multicolumn{4}{|c|}{ FCD type II (isolated) } \\
\hline FCD type lla & Dysmorphic neurons & Yes & Introduce genetic findings of mTOR activation \\
\hline FCD type llb & Dysmorphic neurons and balloon cells & Yes & $\begin{array}{l}\text { Introduce genetic findings of mTOR activation and } \\
\text { new variant at bottom-of-sulcus }\end{array}$ \\
\hline \multicolumn{4}{|c|}{ FCD type III (associated) } \\
\hline FCD type Illa & $\begin{array}{l}\text { Cortical lamination abnormalities in } \\
\text { the temporal lobe associated with } \\
\text { hippocampal sclerosis }\end{array}$ & No & $\begin{array}{l}\text { Molecular and clinical biomarkers needed to } \\
\text { differentiate between secondary (acquired) or } \\
\text { primary etiology }\end{array}$ \\
\hline FCD type IIIb & $\begin{array}{l}\text { Cortical lamination abnormalities adjacent } \\
\text { to a glial or glioneuronal tumor }\end{array}$ & No & $\begin{array}{l}\text { Molecular and clinical biomarkers needed to } \\
\text { differentiate between secondary (acquired) or } \\
\text { primary etiology }\end{array}$ \\
\hline FCD type IIlc & $\begin{array}{l}\text { Cortical lamination abnormalities adjacent } \\
\text { to vascular malformation }\end{array}$ & No & $\begin{array}{l}\text { Molecular and clinical biomarkers needed to } \\
\text { differentiate between secondary (acquired) or } \\
\text { primary etiology }\end{array}$ \\
\hline FCD type IIId & $\begin{array}{l}\text { Cortical lamination abnormalities adjacent } \\
\text { to any other lesion acquired during early } \\
\text { life }\end{array}$ & Yes & $\begin{array}{l}\text { Molecular and clinical biomarkers needed to } \\
\text { differentiate between secondary (acquired) or } \\
\text { primary etiology; introduce FCD type Illd with loss } \\
\text { of layer four neurons in occipital lobe }\end{array}$ \\
\hline
\end{tabular}

ILAE : international league against epilepsy, FCD : focal cortical dysplasia, mTOR : mammalian target of rapamycin 
nitions of dysmorphic neurons (cell size 16-43 $\mu$ m, nucleus diameter 15-28 $\mu \mathrm{m}$, the characteristic Nissl substance and immunohistochemical stainings $)^{5)}$ were emphasized. Moreover, the morphological and immunohistochemical features of balloon cells were detailed ${ }^{5}$.

\section{FCD type III}

The FCD type III is classified into four subcategories (Table 2) based on histological features of principal lesion. If histological examination is not available, it is recommended to use Not Otherwise Specified (NOS). The concept of FCD type III can be simply defined as FCD type I adjacent to another principal lesion. For understanding of this concept, it is better to mention "Temporal lobe sclerosis"15). Thom et al. ${ }^{15)}$ reported approximately $10 \%$ of HS cases showed a horizontal cortical dyslamination with neuronal loss in temporal neocortex. Reflecting their frequent association, co-existence of HS and FCD type I are classified as FCD IIIa (Fig. 7), but not as concurrent type I and type III. Similarly, FCD type I associated with other lesions (such as tumor, vascular lesion, and etc.) were classified as FCD type IIIb (Fig. 8), IIIc, and IIId, respectively.

It is not well known about the pathogenesis of FCD type III. As noted above, it is very difficult to differentiate whether the cortical dyslamination was primary or secondary.

\section{Limitations, genetic progress and prospect}

In our opinion, major limitation of this system is low interobserver agreement, especially, occurring in the assessment of type I and III. In addition, the definition of mMCD was still not clearly established. Nowadays, a lot of research papers regarding genetic information in FCD are published. Detailed review of the updates in genetics of FCD is beyond the purpose of this paper. Briefly, recent genomic data suggests that alteration of mammalian target of rapamycin (mTOR) pathway and mutations of Tuberous sclerosis (TSC) gene play an important role in pathogenesis of $\mathrm{FCD}^{9,10)}$. With the advanced knowledge in genetics, it is needed to update the current classification ${ }^{10)}$. The concept of integrated diagnosis upon clinicopathological and molecular findings has been recently suggested (Table 3). The authors carefully expect that the next classification system of FCD might be similar to the current World Health Organization (WHO) central nervous system (CNS) tumor classification.
There is no "perfect" disease classification system. According to technical progressions and disease paradigm changes, it should be updated. This virtuous cycle will be essential to make better disease classification. This effort will provide a better medical care for patient with epilepsy.

\section{CONFLICTS OF INTEREST}

No potential conflict of interest relevant to this article was reported.

\section{INFORMED CONSENT}

This type of study does not require informed consent.

\section{- Acknowledgements}

This work was supported by the Brain Research Program through the National Research Foundation of Korea (NRF), funded by the Ministry of Science, ICT \& Future Planning (2016M3C7A1913844), NRF-2017R1D1AB03033362 and NRF2018R1A6A1A03023718.

The authors express their gratitude to their good mentors, Dr. Blümcke, I. (Erlangen, Germany), Dr. Sarnat, H.B. (Calgary, Canada), and Dr. Aronica, E. (Amsterdam, Netherland) for their excellent inspirations and advices over the years.

\section{References}

1. Aronica E, Becker AJ, Spreafico R : Malformations of cortical development. Brain Pathol 22 : 380-401, 2012

2. Barkovich AJ, Guerrini R, Kuzniecky RI, Jackson GD, Dobyns WB : A developmental and genetic classification for malformations of cortical development: update 2012. Brain 135 : 1348-1369, 2012

3. Blümcke I, Aronica E, Miyata $H$, Sarnat $H B$, Thom M, Roessler $K$, et al. : International recommendation for a comprehensive neuropathologic workup of epilepsy surgery brain tissue: a consensus task force report from the ILAE commission on diagnostic methods. Epilepsia 57 : 348358,2016

4. Blümcke I, Spreafico R, Haaker G, Coras R, Kobow K, Bien CG, et al. : Histopathological findings in brain tissue obtained during epilepsy surgery. N Engl J Med 377 : 1648-1656, 2017

5. Blümcke I, Thom M, Aronica E, Armstrong DD, Vinters HV, Palmini A, 
et al. : The clinicopathologic spectrum of focal cortical dysplasias: a consensus classification proposed by an ad hoc task force of the ILAE diagnostic methods commission. Epilepsia 52 : 158-174, 2011

6. Cepeda C, André VM, Levine MS, Salamon N, Miyata H, Vinters HV, et al. : Epileptogenesis in pediatric cortical dysplasia: the dysmature cerebral developmental hypothesis. Epilepsy Behav 9 : 219-235, 2006

7. Crome $L:$ Infantile cerebral gliosis with giant nerve cells. J Neurol Neurosurg Psychiatry 20 : 117-124, 1957

8. Hildebrandt M, Pieper T, Winkler P, Kolodziejczyk D, Holthausen $H$, Blümcke I : Neuropathological spectrum of cortical dysplasia in children with severe focal epilepsies. Acta Neuropathol $110: 1-11,2005$

9. Meencke HJ, Veith $\mathrm{G}$ : Migration disturbances in epilepsy. Epilepsy Res Suppl 9 : 31-39; discussion 39-40, 1992

10. Najm IM, Sarnat $H B$, Blümcke I : Review: the international consensus classification of focal cortical dysplasia - a critical update 2018. Neuropathol Appl Neurobiol 44 : 18-31, 2018

11. Palmini A, Najm I, Avanzini G, Babb T, Guerrini R, Foldvary-Schaefer N, et al. : Terminology and classification of the cortical dysplasias. Neurology 62 : S2-S8, 2004

12. Prayson RA : Pathology of epilepsy in Perry A, Brat DJ (eds) : Parctical surgical neuropathology : A diagnostic approach, ed 2. Philadelphia : Elsevier, 2018, pp617-632

13. Taylor DC, Falconer MA, Bruton CJ, Corsellis JA : Focal dysplasia of the cerebral cortex in epilepsy. J Neurol Neurosurg Psychiatry 34 : 369-387, 1971

14. The Free Dictionary : Dysplasia. Available at : https://medical-dictionary.thefreedictionary.com/dysplasia

15. Thom M, Eriksson S, Martinian L, Caboclo LO, McEvoy AW, Duncan JS, et al. : Temporal lobe sclerosis associated with hippocampal sclerosis in temporal lobe epilepsy : neuropathological features. J Neuropathol Exp Neurol 68 : 928-938, 2009

16. Wikipedia : Dysplasia. Available at : https://en.wikipedia.org/wiki/Dysplasia 